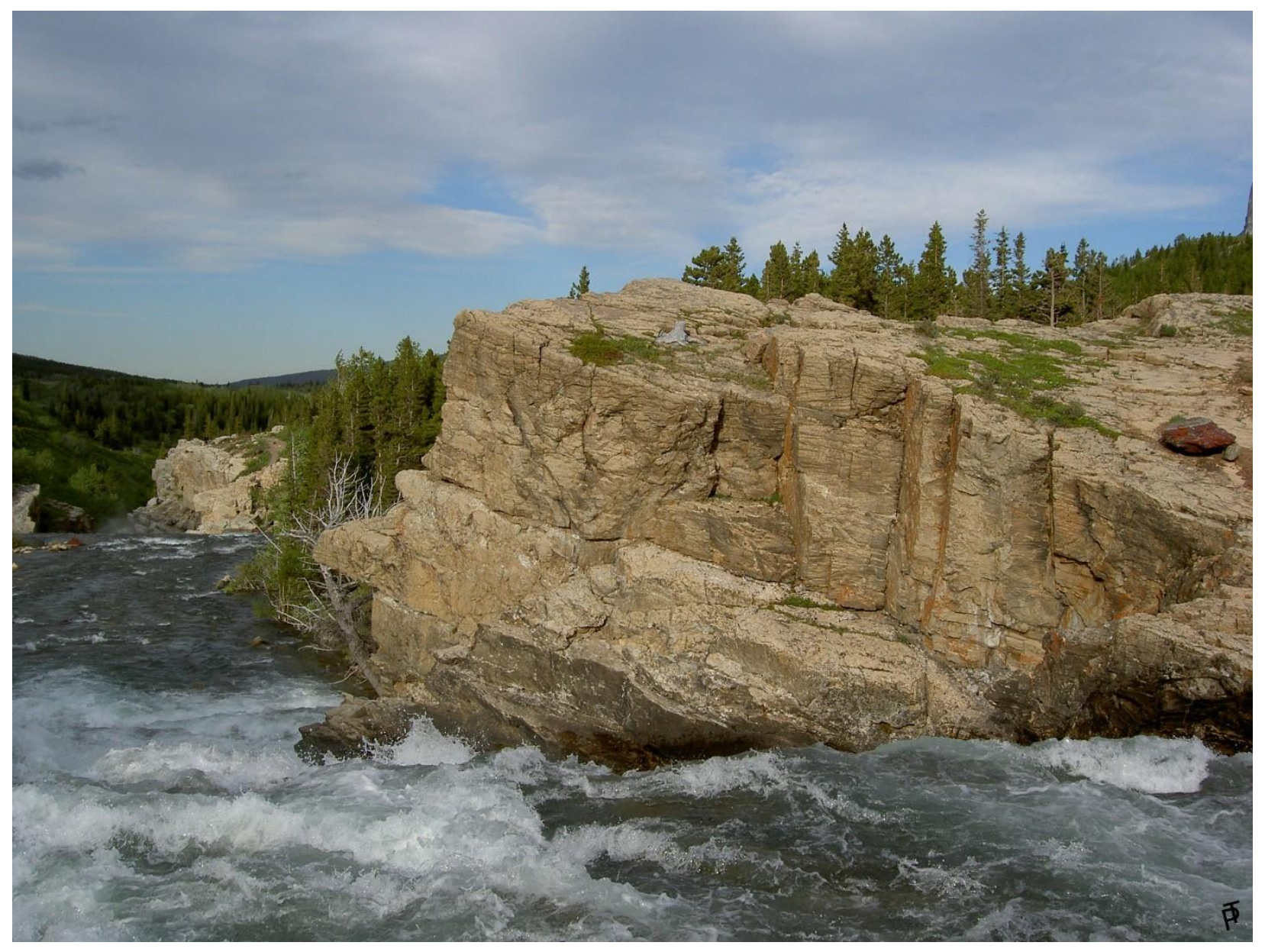

Steadfast by Tiffany Prete 


\section{Cultural and Pedagogical Inquiry Special Issue, Fall 2018}

\section{Spirit and Heart: Indigenous Peoples Contest the Formal and Lived Curricula}

\section{Guest Editors:}

Alesha D. Moffat, York University

Tiffany Prete, University of Alberta

Celia Haig-Brown, York University Cecille DePass, University of Calgary

\section{Hosted by: \\ University of Alberta Libraries}

Access online via:

University of Alberta Libraries, "Cultural and Pedagogical Inquiry" 


\title{
There is Nowhere to Hide: Spirit and Heart in Afro-Indigenous Transformative Engagement
}

\section{An Introduction to the Special Issue}

\author{
Charlotte Henay \\ York University \\ chenay@yorku.ca
}

\begin{abstract}
For these are our bones, our shells
Whisper to me from your edges.

There is a sister in skin.

She is in this room. She marks her territory and you are safe.

Held.

In this body, at this moment.

Within this body of work.
\end{abstract}

- I Am Mountain, Sarah Jane Moore

The words of Sarah Jane Moore's I Am Mountain are resonant with the same space, place, and time that Doreen Spence invokes as she calls the circle in Sharing My Personal Sense of Space (Davis, 2005). This Special Issue of Cultural and Pedagogical Inquiry invites us to be seated in the circle brought together by the featured works. Multidisciplinary, unfettered, and for the most part - unpretentious, the pieces featured here gather around the authors' shared praxes of making space. I write 'for the most part' as provocation, following Margaret Kovach's (2009), incitement to authors and readers alike to consider what happens to Indigenous methodologies when they enter the academy. This provocation echoes the late Stuart Hall's asking, in Cultural Studies and Its Theoretical Legacies, what happens when a politicalintellectual project "tries to develop itself as some kind of coherent theoretical intervention?"

Or, to put the same question in reverse, what happens when [a]...theoretical enterprise tries to engage in pedagogies which enlist the active engagement of individuals and groups, tries to make a difference in the institutional word in which it is located (as cited in Sexton, 2016, p. 12)?

In this circle, we face each other in relationship, mixing it up with the planned and lived curricula confronting us at every moment, in the colonial contexts of our lives and work. This order of business is comprised of the processes and manifestations of the dominant language, institutions, and terms we engage with in formal and informal educational settings. The stories you will find in these pages address critical issues and actions contesting this colonial agenda, following the Comparative and International Education Society of Canada Preconference in May 2017, at the University of Calgary. The works unite around themes of witness; obfuscation of Indigenous lived experiences and historical realities; language as crucial to the maintenance of 
culture and the articulation of truths; questions of indigeneity and decolonization; reciprocal relationships; and the Truth and Reconciliation Commission's 2015 Calls to Action.

Collectively, the submissions question the terms under which Indigenous resurgences are engaged. They come strong with the unequivocal affirmation that the terms are to be negotiated inside of Indigenous community, outside of accusations of epistemic relativism (Debassige \& Brunette-Debassige). These pieces are fluid, many bending form - to make evident the awareness that critique alone, while essential, is insufficient. Something must be offered in return; beyond retroaction, to transformative collaboration in imagining futurities. What might we do, authors and audience, in confronting the violence done to us as Afro-Indigenous Peoples?

Brent Debassige and Candace Brunette-Debassige offer thoughtful commentary on the costs and implications, which they qualify as a "real and omnipresent threat to well-being", of working for transgressive change in the institution. They join Ruth Koleszar-Green and Elizabeth Brulé in a comparative critique of indigenizing versus decolonizing the academy. In so doing, they affirm knowledge as collective - as spirit is collaborative - and gather around the theme of centering Indigenous knowledges as a way to counter erasure, beyond the tokenism of inclusion and incorporation into mainstream agendas. There is consensus, in this issue, around the need for culturally safe spaces for collective storying without fear of reprisal. These spaces welcome "both laughter and tears" (Koleszar-Green), making space for engagement in critical reflection about what we might do in confronting the violence enacted against Afro-Indigenous peoples in the curricula that underwrites the world we live in. Koleszar-Green affirms the need "to displace colonial frameworks" and "insist on introducing epistemological and ontological understanding of our worldviews into the academy." She further grapples with the complexities of unpacking, articulating and memorying protocols interrupted by colonization, in her brilliant articulation of non-Okwehonweh folks as Guests versus Settlers. Ruth makes explicit agreements as living and binding, with a focus on reciprocal relationships and commitments Guests and Hosts make to each other. The article What is a Guest? What is a Settler? looks at the difference between the two terms and ways of being, taking up Tuck \& Yang's (2012) incommensurabilities of decolonization in a pressing acknowledgement of the mutual imbrication of slavery and exploitation in the formation of colonial histories. I follow her conjuring of an anti-colonial conceptualization of blackness' complicated layering within Guest identities, to articulate indigeneity and blackness as inextricable from each other, the establishment of whitestream curricula, and empire-building.

In Red Hope Pedagogies, Cora Weber-Pillwax, Jeannette Sinclair, Claudine Louis, Sarah Auger \& Rebecca Sockbeson offer a call and response poetic retroaction on their experiences "negotiating complexities and tensions of teaching the hard realities of (their) collective history and its ongoing painful legacy," teaching truths as precursor to reconciliation. They speak the pain of what Nombuso Dlamini (2010) refers to in From the Other Side of the Desk, in facing the challenge of redefining truth, as seen by colonial society. In Red Hope Pedagogies' advocacy of remaining hopeful while encountering willful ignorance and violence, lies the question what are the implications of theorizing hope? Who might be its arbiter? Is hope widely accessible, or white-coded? What could happen were we to "wish against hope" (Vitamin D) in a radical affirmation of faith in "the power of grieving and the echo of mourning across generations" (Claudine Louis) as a catalyst for transformative change? Grant Spotted Bull's Missing and Murdered does just that, formulating an account of suffering (Sexton, 2016). Trigger warning. In his powerful visual recounting is the refusal to look away. Multiple stories are represented in 
layered iterations of witness, personal and political. Grant's narration lays bare the embodiment of Missing and Murdered Indigenous Women and Girls and Two-Spirit People (MMIWG2S) in his work, making explicit the brutality he has storied, demanding audiences take responsibility for any misrepresentations.

Gender violence needs its own centering in Afro-Indigenous resurgences, decolonizing, and anti-racist initiatives. I build on Spotted Bull's title, to echo Betasamosake-Simpson's (2012) insistence the "interrogation of heteropatriarchy needs to become part of our decolonizing project" with space made for LGBTQ2S folks' concerns and realities, in communities, ceremonies and representation of leadership. The urgency of this repositioning in our work draws attention to the importance of how we remember, itself a language in need of revitalization. There is a "politics of the imperative" (Sexton, 2016, p. 3) in every vivid piece that follows, where we face ethical questions, and are called to take "risky and courageous decisions" (Te Kawehau Hoskins) in developing productive political practice. I leave you with the consideration of what it entails to develop a collaborative praxis of Afro-Indigenous leadership. Hoskins joins Doreen Spence and Sakihitowin in testimony to cultural ways of being and doing as the lever for the futurities we imagine. How is our thinking impacted by the practices we truck with in the work we do? What happens to our processes for thinking through marginalization and colonial legacies when we labour within dominant frameworks? These systems, policies, practices including the parameters for writing a paper - are not designed to hold our freedom (Kelley, 2016).

In refusing erasure, we generate new futurities. How do what Hoskins names "Indigenous disengagement and oppositional political stances alongside struggles for recognition and inclusion" shape our praxes? How much impact do the academy and whitestream education systems have on the parameters of our teaching, activism and engagement in reciprocal relationships? When does contestation become self-replicating? There is nowhere to hide in circle, we are made vulnerable to each other. In this space what does sovereignty look like? Can a relationship be sovereign? By extension, could it be the teachings and terms that are sovereign? Finally, when we live in other peoples' languages, for many of us the only one we have, what do we mean when we remember the future? 


\section{References}

Betasamosake-Simpson. (2012, June 1). Queering resurgence: Taking on heteropatriarchy in Indigenous nation building. Retrieved from: https://www.leannesimpson.ca/writings/queering-resurgence-taking-on-heteropatriarchyin-indigenous-nation-building

Dlamini, S. N. (2002). From the other side of the desk: Notes on teaching about race when racialised. Race Ethnicity and Education, 5(1), 51-66. http://doi.org/10.1080/13613320120117199

Kelley, R. D. G. (2016). Black Study, Black Struggle. Boston Review, pp. 1-17. Boston, MA.

Kovach, M. (2009). Indigenous methodologies: characteristics, conversations and contexts. Toronto: University of Toronto Press, 2009.

Sexton, J. (2016). Afro-Pessimism: The Unclear Word. Rhizomes: Cultural Studies in Emerging Knowledge, 29(29), 1-21. http://doi.org/10.20415/rhiz/029.e02

Spence, D. (2005). Sharing my personal sense of place. In Davis, A., \& Sandalack, B. A. Excursions into the Cultural Landscapes of Alberta. Calgary, AB: The Nickle Arts Museum.

Tuck, E., \& Wayne Yang, K. (2012). Decolonization is not a metaphor. Decolonization: Indigeneity, Education \& Society, 1(1), 1-40. Retrieved from: http://decolonization.org/index.php/des/article/view/18630/15554

Vitamin D. (n.d.). Wishing against hope: The radical prospects of afro-pessimism [Blog post]. Retrieved from: https://vitamindecolonial.wordpress.com/2016/09/01/wishing-againsthope-the-radical-prospects-of-afro-pessimism/

Cultural and Pedagogical Inquiry, Fall 2018, 10(2), pp. 1-4

ISSN 1916-3460 @ 2018 University of Alberta

http://ejournals.library.ualberta.ca/index.php/cpi/index 